\title{
Doença de Still do Adulto - Um Desafio Diagnóstico na Febre de Origem Indeterminada ${ }^{(*)}$
}

\section{Prezados editores:}

Este caso foi por nós considerado como um desafio diagnóstico, por tratar-se de paciente idoso com quadro de febre de origem desconhecida, visto que em apenas $30 \%$ dos casos, esta doença ocorre após os 35 anos de idade.

A doença de Still do Adulto (DSA) é uma doença rara, e de etiologia desconhecida ${ }^{(1,2)}$. Está entre as causas mais freqüentes de febre de origem indeterminada. Cerca de 75\% dos casos ocorrem entre 16 e 35 anos e sua prevalência é semelhante em ambos os sexo ${ }^{(3-5)}$. O diagnóstico é baseado em achados clínicos e laboratoriais, após a exclusão de outras doenças febris ${ }^{(6-8)}$. Recentemente, vivenciamos o caso de um paciente do sexo masculino, de 59 anos de idade, com história de febre vespertina $\left(40^{\circ} \mathrm{C}\right)$ há um mês, associada a odinofagia e mialgia generalizada. Concomitante apresentava rash cutâneo nos membros inferiores que se tornava mais evidente durante os picos febris. Evoluiu com artralgias, hepatomegalia com disfunção hepática caracterizada por elevação do tempo de atividade de protrombina, hipoalbuminemia, elevação de transaminases $($ AST $=1.041$ e ALT=958 U/1), diarréia transitória e neutrofilia. Foram afastadas doenças infecciosas, virais, neoplásica e do tecido conjuntivo, considerando-se, então, o diagnóstico de doença de Still do adulto. Este paciente apresentava ainda importante elevação de ferritina $(=1.500$ para valores normais de 29 a 300). Hiperferritinemia é encontrada em mais de $70 \%$ dos pacientes com doença de Still ativa e está correlacionada com a atividade da doença, podendo ser usada como marcador, pois seus níveis excedem em muito os encontrados em outra doenças reumáticas ${ }^{(2-5,9)}$. Miyazawa et al. demonstraram que a ferritina sérica é sinte-

\section{REFERÊNCIAS}

1. Evans RH, Mansel RE, Borysiewicz LK, Williams BD: Pirexia of unknown origin. BMJ 314: 83-6, 1997.

2. Schwarz-Eywil M, Heilig B, Bauer H, Breibart A, Pezzutto A: Evaluation of serum ferritin as a marker for adult Still's disease activity. Ann Rheum Dis 51: 683-5, 1992. tizada em histiócitos em proliferação e liberada no plasma como ferritina não glicosilada, caracterizando-se como uma síndrome hemofagocítica. Alguns estudos mostram a correlação negativa entre a saturação de ferro da ferritina e a concentração de ferritina nos pacientes com doença de Still do adulto. Isto sugere que, na doença ativa, a síntese rápida de ferritina supera a taxa de incorporação do ferro na ferritina ${ }^{(10)}$.

A doença de Still do adulto tem uma mortalidade significativa. Causas de óbito incluem infecção, falência hepática, amiloidose, síndrome da angústia respiratória do adulto, falência cardíaca, status epilepticus, coagulação intravascular disseminada e púrpura trombocitopênica trombótica ${ }^{(11)}$.

Ao paciente em questão foi proposto inicialmente tratamento com antiinflamatório não hormonal e antipirético. Após 15 dias de tratamento, o mesmo apresentou artrite no cotovelo direito e manutenção do quadro febril. Nesta ocasião foi iniciado prednisona na dose de $40 \mathrm{mg} / \mathrm{dia}$, associado à hidroxicloroquina $(400 \mathrm{mg} / \mathrm{dia})$. Após três meses de tratamento, houve melhora do quadro clínico e laboratorial.

Marlene Freire Professora adjunta da disciplina de Reumatologia da FMTM

Reginaldo Botelho Teodoro Médico assistente da disciplina de Reumatologia da FMTM

Lília Beatriz Oliveira Residente (R3) em Reumatologia na FMTM

Yves Mirza Scaff Camargo Residente (R2) em Reumatologia na FMTM

3. Sampalis JS, Medsger TA, Fries JF, et al: Risk factors for adult Still's disease. J Rheumatol 23: 2049-50,1996.

4. Lübbe J, Hofer M, Chavaz P, Surat J-H, Borradori L: Adult onset Still's disease with persistent plaques. Brit J Dermatol 141: 710-3, 1999.

5. Akritidis N, Sakkas LI: Adult onset Still's disease. La Presse Médicale 24: 1207-8, 1995.

Trabalho realizado na disciplina de Reumatologia do Departamento de Clínica Médica da Faculdade de Medicina do Triângulo Mineiro (FMTM), Uberaba, MG, Brasil. 
6. Mok CC, Lau CS, Wong RWS: Clinical characteristics, treatment, and outcome of adult onset Still's disease in Southern chinese. J Rheumatol 25: 2345-51, 1998.

7. Lugo-Somolinos A, Sánchez JL: Adult-onset Still's disease. International J Dermatol 34: 490-2, 1995.

8. Min JK, Cho CS, Kim HY, Oh EJ: Bone marrow findings in patients with adult Still's Disease. Scand J Rheumatology 32: 119-212, 2003.
9. Andrès E, Kurtz JE, Perrin A-E, et al: Retrospective monocentric study of 17 patients with adult Still's disease, with special focus on liver abnormalities. Hepato - Gastroenterology 50: 192-5, 2003.

10. Kate JT, Drenth JPH, Kahn M-F, Van Deursen C: Iron saturation of serum ferritin in patients with adult onset Still's disease. J Rheumatol 28: 2213-5, 2001.

11. Phillips WG, Weller R, Handfield-Jones SE, Kobza-Black A: Adult Still's disease. British J Dermatology 130: 511-3,1994. 